\title{
Release of Nitrogen-Containing Bisphosphonates (NBPs) from Hydroxyapatite by Non-NBPs and by Pyrophosphate
}

\author{
Kanan Bando, ${ }^{* a}$ Takefumi Oizumi, ${ }^{b, c}$ Tetsu Takahashi, ${ }^{b}$ Itaru Mizoguchi, ${ }^{a}$ Shunji Sugawara, ${ }^{d}$ and \\ Yasuo Endo ${ }^{b}$ \\ ${ }^{a}$ Division of Orthodontics and Dentofacial Orthopedics, Graduate School of Dentistry, Tohoku University; \\ 4-1 Seiryo-machi, Aoba-ku, Sendai 980-8575, Japan: ${ }^{b}$ Division of Oral and Maxillofacial Surgery, Graduate School \\ of Dentistry, Tohoku University; 4-1 Seiryo-machi, Aoba-ku, Sendai 980-8575, Japan: ${ }^{c}$ Department of Dentistry and \\ Oral Surgery, National Hospital Organization Sendai Medical Center; 2-11-12 Miyagino, Miyagino-ku, Sendai \\ 983-8520, Japan: and ${ }^{d}$ Division of Oral Immunology, Graduate School of Dentistry, Tohoku University; 4-1 Seiryo- \\ machi, Aoba-ku, Sendai 980-8575, Japan.
}

Received April 14, 2021; accepted August 2, 2021

Bisphosphonates (BPs) are major anti-bone-resorptive drugs. Among them, the nitrogen-containing BPs (NBPs) exhibit much stronger anti-bone-resorptive activities than non-nitrogen-containing BPs (non-NBPs). However, BP-related osteonecrosis of the jaw (BRONJ) has been increasing without effective strategies for its prevention or treatment. The release of NBPs (but not non-NBPs) from NBP-accumulated jawbones has been supposed to cause BRONJ, even though non-NBPs (such as etidronate (Eti) and clodronate (Clo)) are given at very high doses because of their low anti-bone-resorptive activities. Our murine experiments have demonstrated that NBPs cause inflammation/necrosis at the injection site, and that Eti and Clo can reduce or prevent the inflammatory/necrotic effects of NBPs by inhibiting their entry into soft-tissue cells. In addition, our preliminary clinical studies suggest that Eti may be useful for treating BRONJ. Notably, Eti, when administered together with an NBP, reduces the latter's anti-bone-resorptive effect. Here, on the basis of the above background, we examined and compared in vitro interactions of NBPs, non-NBPs, and related substances with hydroxyapatite (HA), and obtained the following results. (i) NBPs bind rapidly to HA under pH-neutral conditions. (ii) At high concentrations, Eti and Clo inhibit NBP-binding to HA and rapidly expel HA-bound NBPs (potency Eti $>>$ Clo). (iii) Pyrophosphate also inhibits NBP-binding to HA and expels HAbound NBPs. Based on these results and those reported previously, we discuss (i) possible anti-BRONJ strategies involving the use of Eti and/or Clo to reduce jawbone-accumulated NBPs, and (ii) a possible involvement of pyrophosphate-mediated release of NBPs as a cause of BRONJ.

Key words bisphosphonate; hydroxyapatite; etidronate; clodronate; pyrophosphate; osteonecrosis

\section{INTRODUCTION}

Bisphosphonates (BPs) are important anti-bone-resorptive drugs. ${ }^{1-3)}$ BPs bind strongly to bone, especially to bones exhibiting rapid turnover or inflammation. Due to their high affinity for the hydroxyapatite (HA) of bones, BPs accumulate within bones upon repeated administration. Among the BPs, the nitrogen-containing BPs (NBPs) have anti-boneresorptive activities that are far stronger than those of the non-nitrogen-containing BPs (non-NBPs) ${ }^{2,4)}$ (Supplementary Fig. 1). However, NBPs are known to have inflammatory/necrotic side effects after intravenous administration, as well as various gastrointestinal side effects after oral administration. In particular, since the first reports in 2003, ${ }^{5,6}$ NBP-related osteonecrosis of the jaw (BRONJ) has been increasing without effective clinical strategies. ${ }^{7)}$ In Japan, 263 BRONJ patients were reported in the period 2006-2008, but as many as 4797 during 2011-2013. ${ }^{8)}$

Only two non-NBPs (etidronate (Eti) and clodronate (Clo)) are currently used for osteoporosis. To compensate for their weak anti-bone-resorptive activities, they are given to patients at doses much higher than those of NBPs. ${ }^{1,9)}$ Unlike NBPs, Eti and Clo have no severe inflammatory/necrotic side effects. It is notable that Clo is a BP that can be given intramuscularly as well as orally and intravenously. ${ }^{10)}$
A single injection of a BP into young mice produces a clear sclerotic band in their tibias (we call this the "BP-band") that is detectable by radiography a few weeks after the injection, reflecting an inhibition of bone resorption. By examining the BP-band, we previously obtained the following results. Eti, when administered to mice together with an NBP reduces the anti-bone-resorptive effect of the $\mathrm{NBP},{ }^{11)}$ while such an effect of Clo, if any, is minimal. ${ }^{12)}$ Eti, when administered after an NBP, also reduces the anti-bone-resorptive effect of the NBP. ${ }^{13)}$ Before obtaining those findings, we had reported that Clo can inhibit the inflammatory/necrotic effects of NBPs in mice. ${ }^{14)}$ Our later pharmacological studies indicated that Eti and Clo inhibit the entry of NBPs into soft-tissue cells via inhibition of phosphate transporters. ${ }^{15-17)}$ Taken together, these results suggest that (i) Eti inhibits the binding of an NBP when the two are co-administered, (ii) Eti can expel NBPs that have already accumulated within bones, and (c) Eti may inhibit the entry of the expelled NBPs into soft-tissue cells around the bones, thus preventing the inflammatory/necrotic effects of the expelled NBPs and reducing the anti-boneresorptive activities of NBPs. Our clinical trials to examine the use of Eti as a substitution drug for NBPs suggest that Eti may be useful for reducing the signs of BRONJ. ${ }^{18,19)}$ Here, based on the background described above, we examined and compared the in vitro effects of Eti and Clo on the binding 

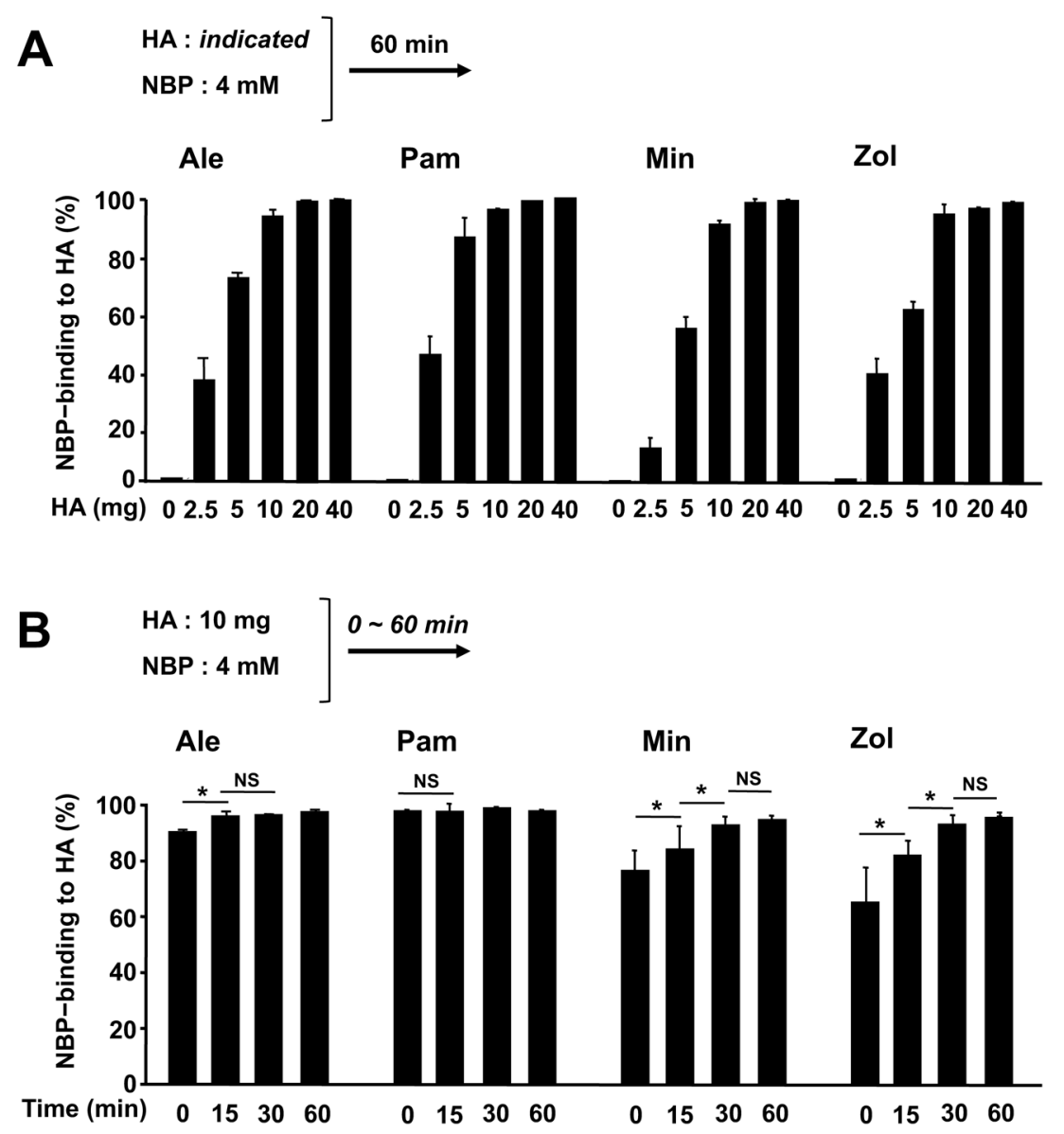

Fig. 1. NBP-Binding to HA

(a) NBP-binding capacity of HA. An indicated amount of HA and $4 \mathrm{mM}$ of a given NBP $(100 \mu \mathrm{L})$ were mixed by pipetting, and the mixture was left standing for $60 \mathrm{~min}$ and then centrifuged. Then, the NBP in the resultant supernatant was measured. (b) NBP-binding velocity to HA. HA $10 \mathrm{mg}$ and $4 \mathrm{mM}$ of a given N-BP $(100 \mu \mathrm{L})$ were mixed by pipetting, and the mixture was left standing for the indicated time before being centrifuged. Finally, the NBP in the resultant supernatant was measured. Each value is the mean \pm S.D. from 4 tubes. ${ }^{*} p<0.05 v s$. indicated group.

of NBPs to HA and on the release of HA-bound NBPs. We focused particularly on the latter because the NBPs released from NBP-accumulated jawbones may play critical roles in the development of BRONJ.

\section{MATERIALS AND METHODS}

Reagents Minodronate- $\mathrm{H}_{2} \mathrm{O}$ (Min) and pamidronate2Na-anhydrous (Pam) were from LKT Laboratories, Inc. (St. Paul, MN, U.S.A.). 2,4,6-Trinitrobenzene sulfonic acid hydrate (TNBS), alendronate- $\mathrm{Na} \cdot 3 \mathrm{H}_{2} \mathrm{O}$ (Ale), zoledronate$2 \mathrm{Na} \cdot 4 \mathrm{H}_{2} \mathrm{O}(\mathrm{Zol})$, risedronate- $\mathrm{Na} \cdot 2.5 \mathrm{H}_{2} \mathrm{O}$ (Ris), and etidronate$2 \mathrm{Na} \cdot$ anhydrous (Eti) were purchased from Tokyo Kasei (Tokyo, Japan). Phosphate- $\mathrm{Na} \cdot 2 \mathrm{H}_{2} \mathrm{O}$ (Pi), dimethylsulfoxide (DMSO), $\mathrm{CaCl}_{2} \cdot 2 \mathrm{H}_{2} \mathrm{O}$, and $\mathrm{MgCl}_{2} \cdot 6 \mathrm{H}_{2} \mathrm{O}$ were from Nacalai Tesque (Kyoto, Japan). Clodronate-2Na·anhydrous (Clo) and hydroxyapatite (HA) (\#677418: particle size $\leq 200 \mathrm{~nm}$, specific surface area $\geq 9.4 \mathrm{~m}^{2} / \mathrm{g}$ ) were from Sigma-Aldrich (St. Louis, MO, U.S.A.). Pyrophosphate-4Na-anhydrous (PPi) and phosphonoformic acid (PFA) were from Alfa Aesar (Tewksbury, MA, U.S.A.). Phosphonoacetic acid (PAA) was from Wako (Osaka, Japan).

Preparation of BP Solutions BPs were dissolved in distilled water. Unless otherwise indicated, solutions were adjusted to $\mathrm{pH} 7$ with $\mathrm{NaOH}$ solution. In some experiments, solutions were adjusted to the indicated $\mathrm{pH}$ values with $\mathrm{NaOH}$ or $\mathrm{HCl}$ solutions. Then, the concentration of the BP solutions was adjusted to that required with distilled water.

Preparation of HA HA was suspended in distilled water, with the $\mathrm{pH}$ of the suspension being adjusted to 7 with $\mathrm{NaOH}$ solution or, in some experiments, adjusted to the indicated $\mathrm{pH}$ values with $\mathrm{NaOH}$ or $\mathrm{HCl}$ solutions. Then, the concentration of the HA suspensions was adjusted to $100 \mathrm{mg} / \mathrm{mL}$ with distilled water and used as indicated. The required amount of the HA suspension $(100 \mu \mathrm{L}$; i.e., $10 \mathrm{mg}$ HA, in most experiments) was transferred to a test tube. Then, the tube was centrifuged at $10000 \times \boldsymbol{g}$ for $5 \mathrm{~min}$, and the supernatant was removed. The resultant precipitate was used as HA.

Binding of NBPs to HA To a tube containing HA, $100 \mu \mathrm{L}$ solution containing an NBP alone or NBP plus a test material(s) was added, and the contents of the tube mixed by pipetting. Then, the tube was left standing at room temperature for approx. $60 \mathrm{~min}$ before being centrifuged at $10000 \times \boldsymbol{g}$ for $5 \mathrm{~min}$. The resultant supernatant was subjected to measurement of the amount of the NBP. The amount of the NBP bound to the HA was expressed as a percentage of the NBP added.

Release of an NBP from NBP-Bound HA NBP-bound HA (abbreviated "NBP-HA") was prepared by mixing $10 \mathrm{mg}$ $\mathrm{HA}$ and $100 \mu \mathrm{L}$ NBP (concentration indicated) and removal of the supernatant following centrifugation. To an NBP-HA, a solution of a test material $(\mathrm{s})(100 \mu \mathrm{L})$ was added, and the 

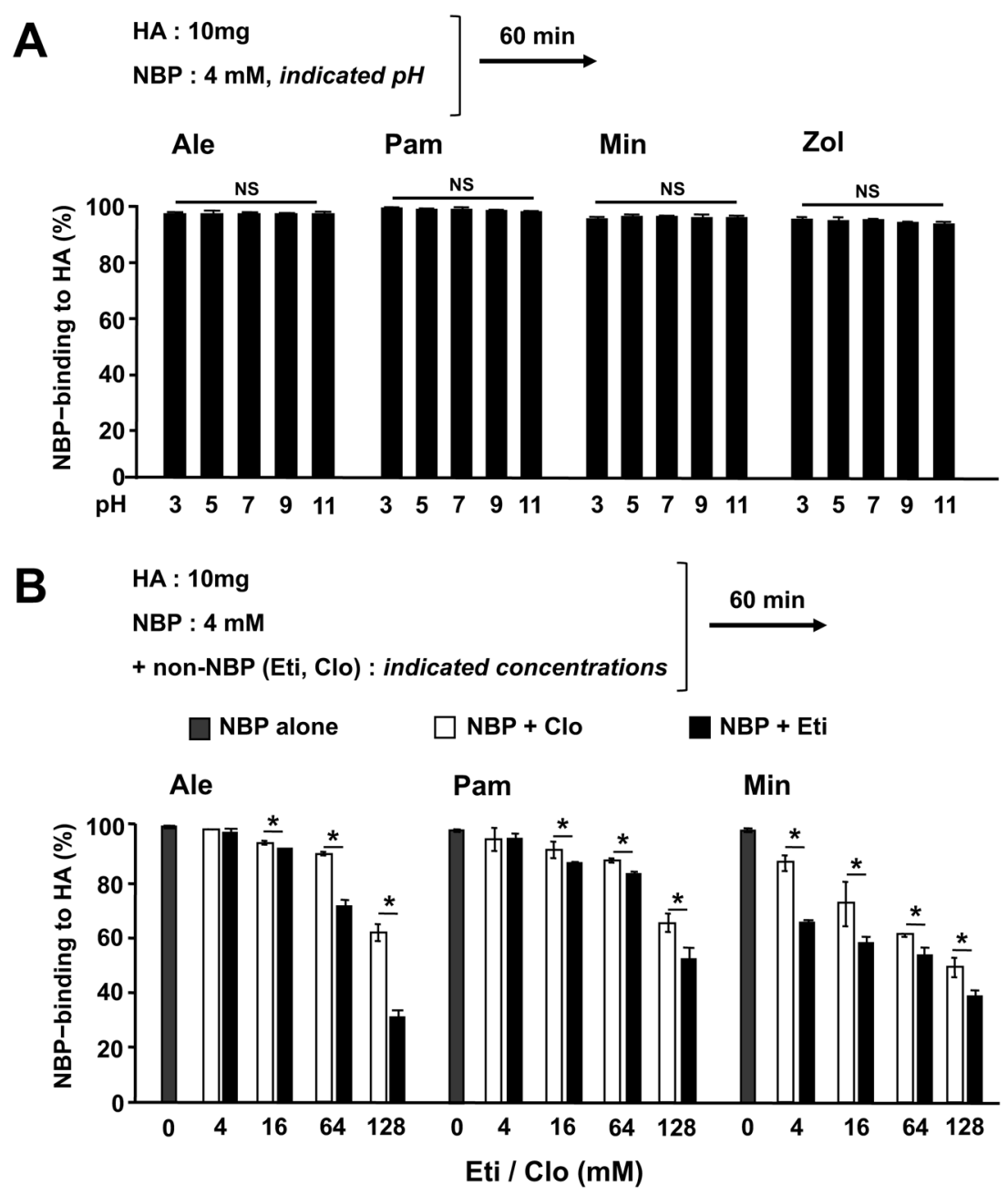

Fig. 2. Effects of $\mathrm{pH}$ and the Non-NBPs Eti and Clo on NBP-Binding to HA

(a) Effects of $\mathrm{pH}$ on the binding of NBPs to HA. HA $10 \mathrm{mg}$ and $4 \mathrm{mM}$ of a given NBP $(100 \mu \mathrm{L})$ (pH of each having been adjusted as indicated) were mixed by pipetting, and the mixture was left standing for $60 \mathrm{~min}$ before being centrifuged. Finally, the NBP in the resultant supernatant was measured. (b) Effects of Eti and Clo on the binding of NBPs to HA. HA $10 \mathrm{mg}$ and $100 \mu \mathrm{L}$ of a solution containing $4 \mathrm{mM}$ of an NBP and the indicated concentration of Eti or Clo were mixed by pipetting, and the mixture was left standing for $60 \mathrm{~min}$ before being centrifuged. Finally, the NBP in the resultant supernatant was measured. Each value is the mean \pm S.D. from 4 tubes. ${ }^{*} p<0.05$ vs. indicated group.

contents of the tube were mixed by pipetting. Then, the tube was left standing at room temperature for approx. $60 \mathrm{~min}$ before being centrifuged at $10000 \times \boldsymbol{g}$ for $5 \mathrm{~min}$. The resultant supernatant was subjected to measurement of the amount of the NBP, and the amount of the NBP released from the NBP$\mathrm{HA}$ was calculated and expressed as a percentage of the NBP bound to HA.

Measurement of Pam and Ale Pam and Ale were measured spectrophotometrically (absorbance at $450 \mathrm{~nm}$ ) after reaction of their amino group with 2,4,6-trinitrobenzene sulfonate (TNBS) ${ }^{20)}$ To each well of a 96-well plate, $200 \mu \mathrm{L}$ borate buffer $(0.2 \mathrm{M}, \mathrm{pH} 8.5), 100 \mu \mathrm{L}$ TNBS solution $(1 \mathrm{mg} / \mathrm{mL}$ DMSO), and $10 \mu \mathrm{L}$ of the solution of Pam or Ale were added. After completing the TNBS reaction for $30 \mathrm{~min}$ at $37^{\circ} \mathrm{C}$, the absorbance of the reaction mixture at $450 \mathrm{~nm}$ was measured.

Measurement of Zol, Ris, and Min Zol, Ris, and Min were measured spectrophotometrically by measuring their native UV absorbance (at $220 \mathrm{~nm}$ for Zol and Ris and at $290 \mathrm{~nm}$ for Min). However, in the presence of a large amount of Eti and/or Clo, Zol and Ris could not be measured because Eti and Clo, at high concentrations, also exhibit UV absorption at around $220 \mathrm{~nm}$ and therefore disturb the measurement of
Zol and Ris (e.g., the absorbances at $220 \mathrm{~nm}$ of $4 \mathrm{mM} \mathrm{Zol,}$ $4 \mathrm{mM}$ Ris, $150 \mathrm{mM}$ Eti, and $150 \mathrm{mM}$ Clo are 1.75, 1.9, 0.5, and 1.5, respectively). Fortunately, Min could be measured even in the presence of a large amount of Eti and/or Clo. The UV absorbance of a given solution was measured by using a UV-star 96-well plate (Greiner, Frickenhausen, Germany) and a FlexStation 3 microplate reader (Molecular Devices, CA, U.S.A.).

Statistical Analysis Experimental values are given as the mean \pm standard deviation (S.D.) from 4 tubes. Sample size was based on an $\alpha$ error of 0.05 and a $\beta$ error of 0.2 using power analysis. The statistical significance of differences was analyzed using a Bonferroni multiple comparison test after ANOVA with the aid of InStat software (InStat, Scottsdale, AZ, U.S.A.). The results shown for a given experiment were confirmed by repeating the experiment at least once more.

\section{RESULTS}

NBP-Binding to HA Figure 1A shows that in spite of structural differences, with each NBP almost $100 \%$ of $100 \mu \mathrm{L}$ of a $4 \mathrm{mM}$ solution of the NBP binds to about $10 \mathrm{mg}$ HA. 

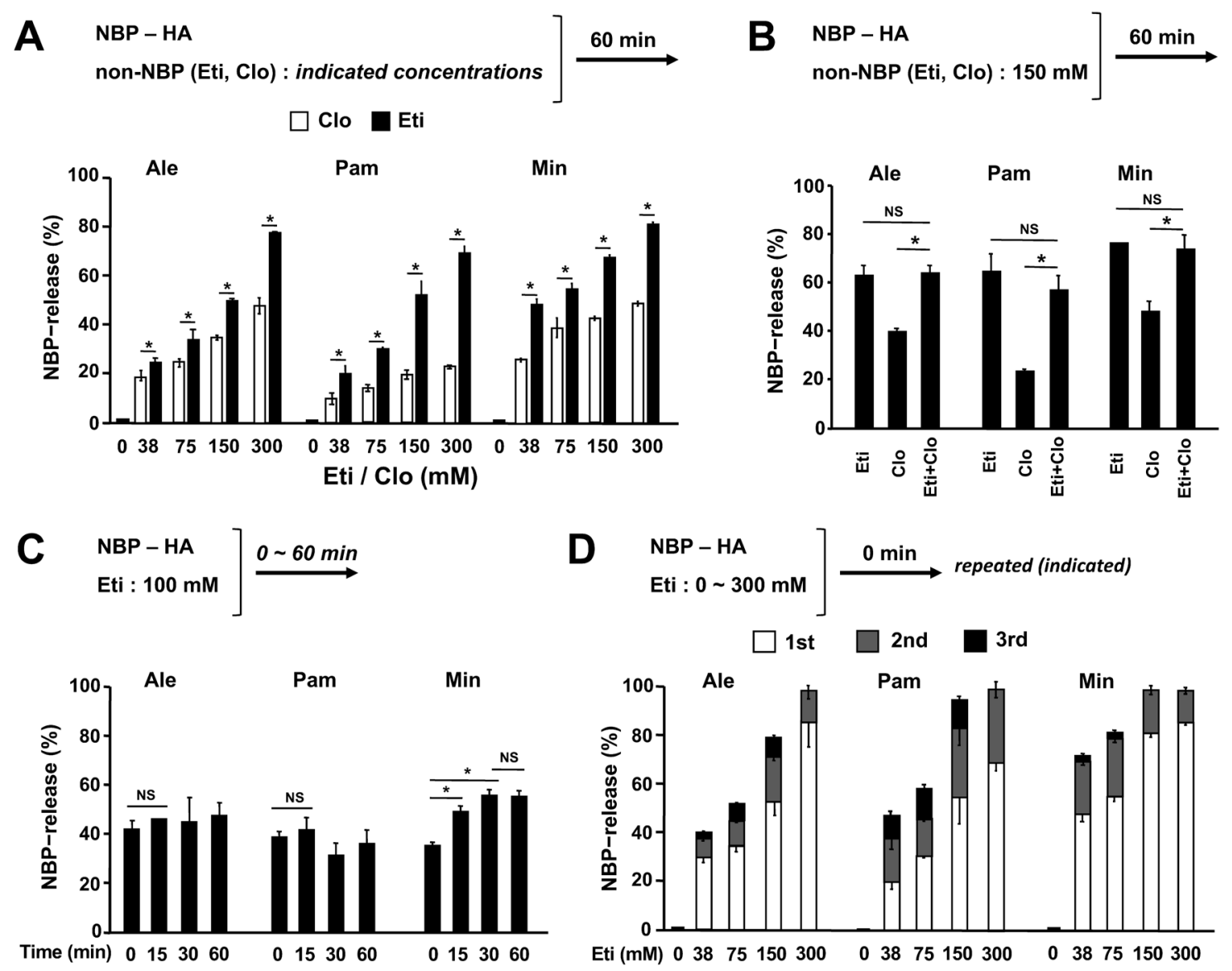

Fig. 3. Effects of Eti and Clo on NBP-Release from NBP( $4 \mathrm{mM})$-HA

In these experiments, $\mathrm{NBP}(4 \mathrm{mM})$-HA was used. $(\mathrm{a}, \mathrm{b})$ Effects of concentrations of Eti and Clo. To each NBP-HA, $100 \mu \mathrm{L}$ of the indicated concentration of Eti, Clo, or both was added and they were mixed by pipetting, left standing for $60 \mathrm{~min}$, and the mixture was centrifuged and the resultant supernatant subjected to measurement of the N-BP. (c) NBP-releasing velocity from HA. NBP( $4 \mathrm{mM})$-HA and $100 \mathrm{mM}$ Eti $(100 \mu \mathrm{L})$ were mixed by pipetting. Then, the mixture was left standing for the indicate time and centrifuged, and the resultant supernatant was subjected to measurement of the NBP. (d) Effect of repeated treatment with Eti. NBP(4 mM)-HA was mixed with Eti (concentration as indicated) by pipetting without standing, and the supernatant obtained by centrifugation immediately after the mixing was subjected to measurement of the NBP. This treatment was performed three times. Each value is the mean \pm S.D. from 4 tubes. ${ }^{*} p<0.05 v s$. indicated group.

This means that (i) the $10 \mathrm{mg}$ HA used in the present study is almost completely saturated with 400 nmols of an NBP, and thus (ii) when $10 \mathrm{mg}$ HA was mixed with $100 \mu \mathrm{L}$ of $4 \mathrm{mM}$ of an NBP solution, almost no free NBP (i.e., not attached to $\mathrm{HA}$ ) is present in the mixture. Figure $1 \mathrm{~B}$ shows that most of each NBP became bound to HA during the mixing (pipetting), although Min and Zol take a somewhat longer time than Ale and Pam for complete binding. Figure 2A shows that at $\mathrm{pH}$ values from 3-11, all the tested NBPs bind almost completely to HA within $60 \mathrm{~min}$, indicating that NBPs exhibit potent affinities for $\mathrm{HA}$ over a wide $\mathrm{pH}$ range. Figure $2 \mathrm{~B}$ shows that the non-NBPs Eti and Clo each concentration-dependently (16-128 mM) reduce NBP-binding to HA for all of the N-BPs tested, indicating that NBPs and non-NBPs bind competitively to HA. In this experiment, Zol was not tested because Eti and Clo disturb the measurement of Zol (see Materials and Methods).

Effects of Eti and Clo on NBP-Bound HA (NBP-HA) If an NBP-bound HA is not saturated with an NBP, then when the NBP is released from the HA, the released NBP might immediately reattach to the HA. In the following experiments, to avoid that happening, we used HA saturated with an NBP, i.e., each NBP-bound HA was prepared from $10 \mathrm{mg} \mathrm{HA}$ and $100 \mu \mathrm{L}$ of $4 \mathrm{mM}$ NBP (abbreviated "NBP(4mM)-HA"). Thus, the HA is nearly saturated with the relevant NBP. Figure $3 \mathrm{~A}$ shows that Eti and Clo concentration-dependently release each NBP. For each NBP, about $80 \%$ of the amount bound to HA was released by $300 \mathrm{mM}$ Eti, while the release induced by $300 \mathrm{mM}$ Clo was smaller. As shown in Fig. 3B, a combination of Eti and Clo (Eti $+\mathrm{Clo}$ ), each $150 \mathrm{mM}$, produced no detectable additive effect on the release of N-BPs from HA, indicating affinities for $\mathrm{HA}$ of Eti $>>$ Clo. Figure $3 \mathrm{C}$ shows that $30-40 \%$ of each NBP is released during mixing, although the release of Min is slightly slower than those of Ale and Pam. In these experiments, the mixing was carried out 20-30 times during 15-20s until each NBP-HA in the tube was completely dispersed. Such mixing with $300 \mathrm{mM}$ Eti two or three times in total resulted in complete release or removal of each NBP from HA (Fig. 3D).

Effects of pH on NBP-Release by Eti As shown in Fig. $2 \mathrm{~A}$, the binding of NBPs to HA was not modified by $\mathrm{pH}$ under the conditions tested. However, Fig. 4A shows that the release of NBPs bound to HA by Eti is markedly affected by $\mathrm{pH}$; i.e., the release of Ale and Pam increased with the increase in $\mathrm{pH}$, while the release of Min was maximal at $\mathrm{pH} 5$.

NBP-Binding to Non-NBP(4 mM)-HA As shown in Fig. $3 \mathrm{~A}$, for NBP-release from NBP-bound HA, a high concentration (approx. $300 \mathrm{mM}$ ) of non-NBP (Eti or Clo) was required. However, Fig. 4B shows that the NBPs tested, even at $4 \mathrm{mM}$, almost entirely bind to non-NBP( $4 \mathrm{mM})$-bound HA, indicating 


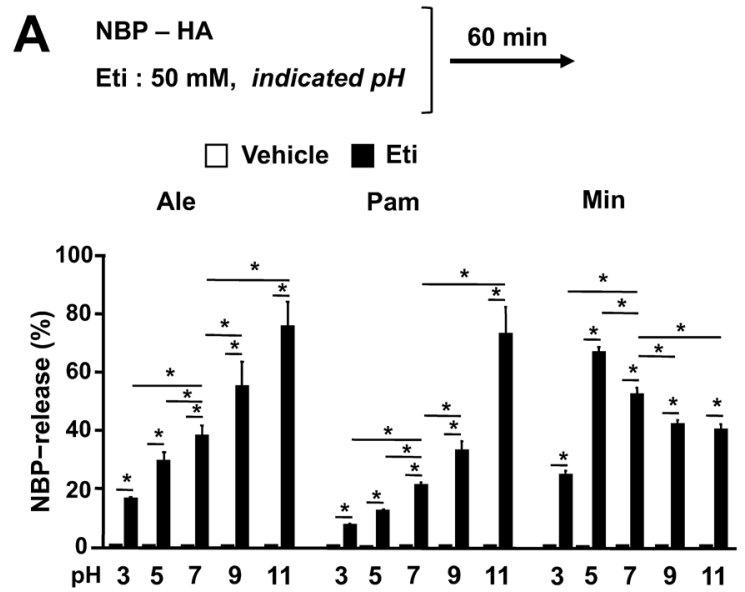

B $\left.\begin{array}{l}\text { non-NBP - HA } \\ \mathrm{NBP}: 4 \mathrm{mM}\end{array}\right] \stackrel{60 \mathrm{~min}}{\longrightarrow}$

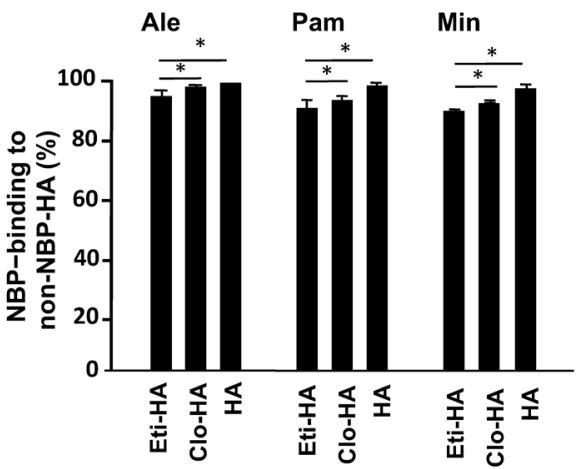

C $\underset{\text { indicated substances }}{\mathrm{NBP}-\mathrm{HA}}] \stackrel{60 \mathrm{~min}}{\longrightarrow}$

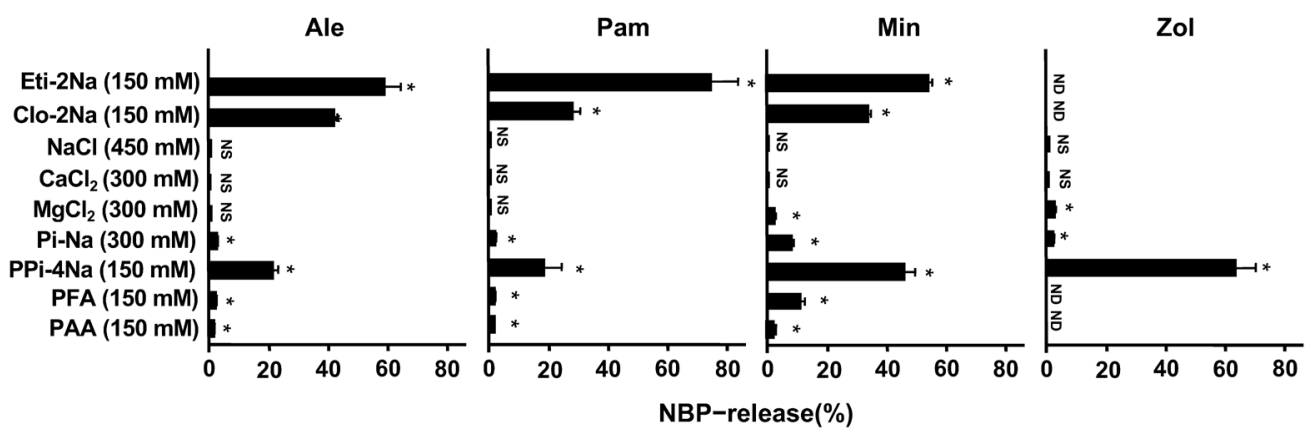

Fig. 4. Additional Properties of NBP(4mM)-HA

In these experiments, NBP( $4 \mathrm{mM})$-HA was used. (a) Effects of $\mathrm{pH}$ on Eti-induced NBP-release from HA. HA-NBP and $50 \mathrm{mM}$ Eti (100 $\mu \mathrm{L}$ ), with the pH adjusted as indicated, were mixed by pipetting and left standing for $60 \mathrm{~min}$, and the mixture was then centrifuged and the resultant supernatant subjected to measurement of the NBP. (b) Effects of Eti or Clo bound to HA (Eti-HA or Clo-HA) on NBP-binding to HA. HA-Eti or HA-Clo was prepared from HA $10 \mathrm{mg}$ and $4 \mathrm{mM}$ Eti or Clo (100 $\mu$ L). They were mixed with $4 \mathrm{mM}$ of a given NBP $(100 \mu \mathrm{L})$ by pipetting and the mixture left standing for $60 \mathrm{~min}$. Then, the mixture was centrifuged and the resultant supernatant subjected to measurement of the NBP. (c) Effects of BP-related substances on NBP-release from NBP-HA. NBP(4 mM)-HA and the indicated test substance (100 $\mu$ L) were mixed by pipetting and the mixture left standing for $60 \mathrm{~min}$. Then, the mixture was centrifuged and the resultant supernatant subjected to measurement of the NBP. Eti, Clo, PFA, and PAA exhibited a UV spectrum at $220 \mathrm{~nm}$. So, their effects on Zol could not be measured in the present study. Data were compared vs. those obtained from distilled water (data not shown). Each value is the mean \pm S.D. from 4 tubes. ${ }^{*} p<0.05 v s$. distilled water group.

that the affinities for HA are NBPs (Ale, Pam, Min) $>>$ nonNBPs (Eti and Clo).

Effects of BP- and HA-Related Substances on NBPRelease BPs are analogs of PPi, and the BPs used in the present study are sodium salts, except Min. So, we examined whether $\mathrm{NaCl}, \mathrm{PPi}$, and PPi-related substances (Pi, PFA, and PAA) can release NBPs from $\mathrm{NBP}(4 \mathrm{mM})-\mathrm{HA}$. Figure $4 \mathrm{C}$ shows that although effects of 300 and $450 \mathrm{mM} \mathrm{NaCl}$ are absent, $300 \mathrm{mM} \mathrm{Pi}, 150 \mathrm{mM}$ PFA, and $150 \mathrm{mM}$ PAA slightly but significantly release the NBPs. In this experiment, we could measure Zol, too, because PPi does not disturb the measurement of Zol. Interestingly, $150 \mathrm{mM}$ PPi markedly releases all the NBPs tested. For Ale and Pam, the releasing effects are Eti $>$ Clo $>$ PPi. However, for Min, the releasing effects are Eti $\geq P P i$. $\mathrm{Ca}^{2+}$ is a component of $\mathrm{HA}$, and $\mathrm{Mg}^{2+}$ easily substitutes for the $\mathrm{Ca}^{2+}$. However, even at $300 \mathrm{mM}$, they exhibit no significant effects on NBP-release from HA. Histamine, putrescine, and spermidine are basic substances, and their productions are known to be increased at inflammatory sites. So, they might interact with the $\mathrm{PO}_{4}{ }^{3-}$ in $\mathrm{HA}$ in vivo. However, none of them, at $150 \mathrm{mM}$, exhibited a detectable effect (data not shown).
Effects of $\mathrm{pH}$ on the PPi-Induced NBP-Release Figure 5A shows that the release of Ale and Pam from HA increases as $\mathrm{pH}$ increases. However, the release of Min was maximal at $\mathrm{pH}$, and the release of $\mathrm{Zol}$ increased with the increase in $\mathrm{pH}$ and reached near maximum at $\mathrm{pH} 7$.

Effects of $\mathrm{Ca}^{2+}, \mathrm{Mg}^{2+}$, and Amines on the PPi-Induced NBP-Release As shown in Fig. $4 \mathrm{C}, \mathrm{Ca}^{2+}, \mathrm{Mg}^{2+}$, and amines, by themselves, exhibited no detectable effects on NBP-release from HA. In the present experiments, however, we could not study the effects of $\mathrm{Ca}^{2+}$ and $\mathrm{Mg}^{2+}$ on PPi-induced NBPrelease from $\mathrm{HA}$ because $\mathrm{CaCl}_{2}$ and $\mathrm{MgCl}_{2}$ each formed insoluble product when mixed with PPi. Concerning histamine, putrescine, and spermidine, none of them modified the PPiinduced release of Min from HA (Fig. 5B).

Experiments Using $2 \mathrm{mM}$ NBPs (a Concentration That Does Not Saturate HA (10 mg)) As shown in Fig. 1B, for complete binding of $4 \mathrm{mM}$ NBPs to HA, Min and Zol required a longer time than Ale and Pam. In addition, the release of Min from HA induced by Eti was slower than those of Ale and Pam (Fig. 3C). We suspected these differences might be due to steric hindrance, because the molecular sizes of Min and Zol are greater than those of Ale and Pam, and $4 \mathrm{mM}$ is 
$\left.\begin{array}{l}\mathrm{NBP}-\mathrm{HA} \\ \mathrm{PPi}: 150 \mathrm{mM} \text {, indicated } \mathrm{pH}\end{array}\right] \stackrel{60 \mathrm{~min}}{\longrightarrow}$
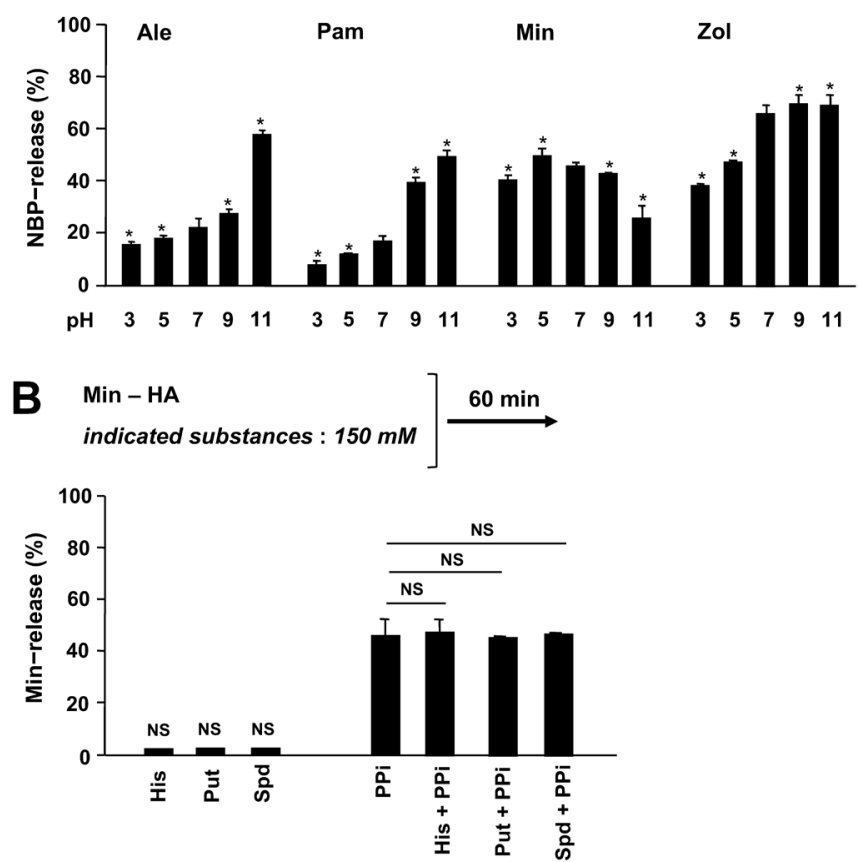

Fig. 5. Effects of $\mathrm{pH}$ and Amines on PPi-Induced NBP-Release from NBP-HA

(a) Effects of pH. NBP( $4 \mathrm{mM})-\mathrm{HA}$ and $150 \mathrm{mM}$ PPi $(100 \mu \mathrm{L})$, with the $\mathrm{pH}$ adjusted as indicated, were mixed by pipetting and left standing for $60 \mathrm{~min}$, and the mixture was the centrifuged and the resultant supernatant subjected to measurement of the NBP. $* p<0.05 v s$. $\mathrm{pH}$ 7. (b) Effects of histamine (H), putrescine (Put), and spermidine (Spd). $\operatorname{Min}(4 \mathrm{mM})-\mathrm{HA}$ and $100 \mu \mathrm{L}$ of a solution of a test substance(s) were mixed by pipetting and left standing for $60 \mathrm{~min}$ before the mixture was centrifuged and the resultant supernatant subjected to measurement of the NBP.

the concentration that nearly saturates $10 \mathrm{mg}$ HA with each NBP (Fig. 1A). So, in the following experiments, $2 \mathrm{mM} \mathrm{NBPs}$ was used. At this concentration, NBPs bind rapidly to HA (Fig. 6A) and are released rapidly from HA (Fig. 6B). In the experiments using $4 \mathrm{mM} \mathrm{NBPs,}$ the order of NBP-releasing effects was Eti $>\mathrm{Clo}>\mathrm{PPi}$ for Ale and Pam, but Eti $\geq \mathrm{PPi} \geq$ Clo for Min (Fig. 4C). Figure 6C shows that these orders are the same in the experiments using $2 \mathrm{mM}$ NBPs, too. In this experiment, like Min and Zol, Ris too is released by PPi with the magnitude of the effect being similar to those on Min and Zol; i.e., the potency to release Min, Zol, and Ris may be Eti $\geq$ PPi $>$ Clo.

Effects of PPi, $\mathrm{Pi}, \mathrm{Ca}^{2+}, \mathrm{Mg}^{2+}$, and Amines on NBPBinding to HA As shown in Fig. 7, PPi reduced the binding of all the NBPs tested, with its effects on Min, Zol, and Ris being greater than those on Ale and Pam. Pi also reduced the binding of all the NBPs tested, but the magnitude of the effects was very small. Although $\mathrm{CaCl}_{2}$ exhibited no effects, $\mathrm{MgCl}_{2}$ slightly reduced the binding of Min, Zol, and Ris. Concerning the effects of amines, we could measure only Min, because the amines reacted with TNBS and exhibited UV absorbance at $220 \mathrm{~nm}$ (used for measuring Zol and Ris). None of the amines tested reduced the binding of Min to HA.

As shown in Fig. 6C, the NBP-releasing effects of PPi were greater for Min, Zol, and Ris than for Ale and Pam. Thus, it was of interest how PPi might inhibit the binding of each NBP to HA. So, finally, we compared the inhibitory effects of various concentrations of PPi among all the NBPs used in the present study (Fig. 8). Interestingly, again we found that the effects of PPi were greater for Min, Zol, and Ris than for Ale and Pam.

Might the NBP Released from HA Have a Changed Ability to Bind to HA? Finally, we examined whether the NBP released from HA retains its ability to bind HA. Although the $\mathrm{P}-\mathrm{C}-\mathrm{P}$ bond of BPs is a structure that is stable against hydrolytic destruction, we cannot rule out the possibility that some unknown mechanisms might alter the ability of the released NBPs to bind to HA. However, the result shown in Supplementary Fig. 2 demonstrates that the NBP Ale released from HA has an unchanged ability to bind to HA (versus Ale not released from HA).

\section{DISCUSSION}

In the present study, by employing the TNBS-reaction or UV spectrometry, we were able to measure NBPs in the presence of high concentrations of Eti, Clo, or PPi and to evaluate NBP-binding to HA and NBP-release from NBP-bound HA. The notable findings are summarized in Table 1.

NBPs possess both negative and positive charges, and HA is also composed of cationic and anionic ions (Supplementary Fig. 3). Thus, interactions between NBP and HA might be modified by $\mathrm{pH}$ and/or the presence of ionic substances. Indeed, Eti, Clo, and PPi markedly modified them, and the NBP-release from HA induced by Eti or PPi was markedly modified by $\mathrm{pH}$. In contrast, $\mathrm{Ca}^{2+}$ and basic biogenic amines (histamine, putrescine, and spermidine) exhibited no detectable effects, while $\mathrm{Mg}^{2+}$ and $\mathrm{Pi}$ were only slightly inhibitory on NBP-binding to HA.

The velocities of both NBP-binding to HA and NBP-release from NBP-bound HA were very rapid under an unsaturated concentration of NBPs, although for complete binding to HA and for complete release from HA, Min and Zol required a somewhat longer standing time than did Ale and Pam. In addition, the effects of PPi on both NBP-binding to HA and NBP-release from HA were greater for Min, Zol, and Ris than for Ale and Pam, while the effects of Pi were minimal. Unlike those of PPi, the effects of PFA and PAA were also very small. These results suggest that, in addition to positive and negative charges, steric hindrance may also modify the interactions between NBPs and HA. The fact that Eti, Clo, and $\mathrm{PPi}$ (but not $\mathrm{Pi}$ ) with a $\mathrm{P}-\mathrm{C}-\mathrm{P}$ or $\mathrm{P}-\mathrm{O}-\mathrm{P}$ structure profoundly affect the interactions between NBPs and HA indicates that the sterically oriented negative charges of the two phosphate residues are critically important in both NBP-binding to HA and NBP-removal from HA.

In the present in vitro experiments, NBPs bound to HA were demonstrated to be released by Eti and Clo (both nonBPs) and by PPi. As described in Introduction, NBPs are supposed to enter soft-tissue cells via phosphate transporters (SLC20 and/or SLC34). ${ }^{15-17)}$ In contrast, the non-NBPs Eti and Clo have been shown to be not retained within soft tissues after their intravenous injection into mice. ${ }^{21)}$ Thus, if we consider the in vivo environment, a number of possibilities for the fate of the released NBPs suggest themselves: (a) rebinding or reattachment to bones, (b) entry into soft-tissue cells around the bone that released the NBP, and (c) excretion. When the bones are not saturated with an NBP, the released NBP might rebind to the non-saturated sites in the bones. In that case, 


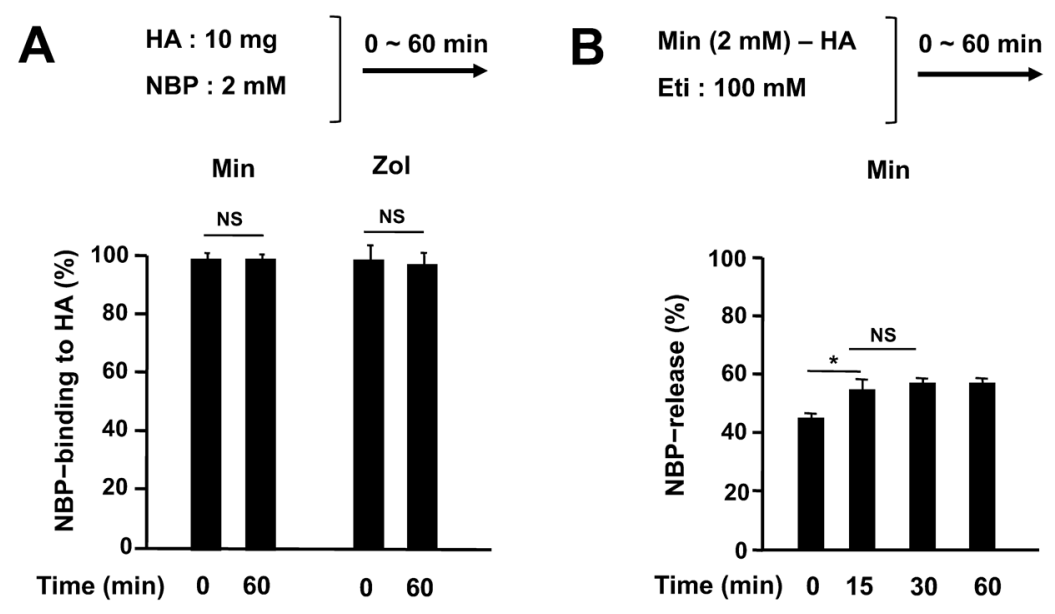

\section{$\left.\begin{array}{l}\text { C } \\ \text { Eti, Clo, PPi : } 150 \mathrm{mM}\end{array}\right] \stackrel{60 \mathrm{~min}}{\longrightarrow}$}

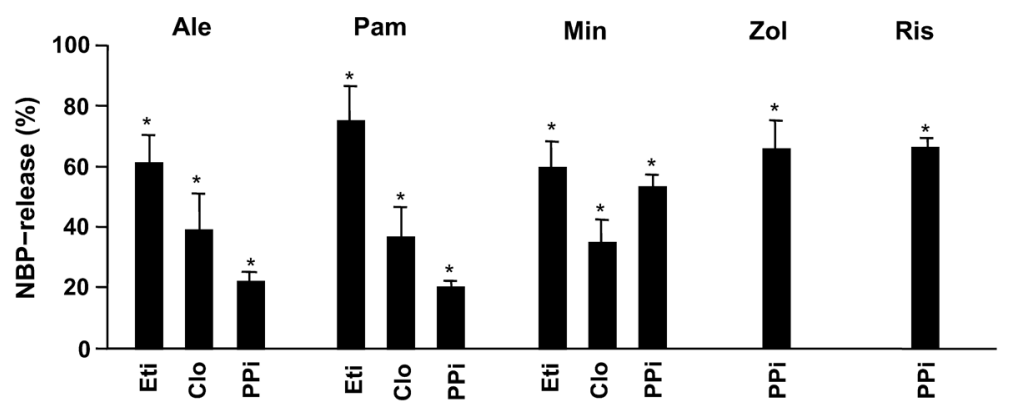

Fig. 6. Properties of NBP(2 mM)-HA

(a) NBP-binding velocity to HA. HA $10 \mathrm{mg}$ and $2 \mathrm{mM}$ of a given N-BP $(100 \mu \mathrm{L})$ were mixed by pipetting, and the mixture was left standing for the indicated time, and then centrifuged. Finally, the NBP in the resultant supernatant was measured. (b) NBP-releasing velocity. NBP( $2 \mathrm{mM})-\mathrm{HA}$ and $100 \mathrm{mM}$ Eti $(100 \mu \mathrm{L})$ were mixed by pipetting. Then, the mixture was left standing for the indicated time and centrifuged, and the resultant supernatant was subjected to measurement of the NBP. Each value is the mean \pm S.D. from 4 tubes. ${ }^{*} p<0.05 v$ s. indicated group. (c) Effects of Eti, Clo, and PPi on NBP-release from NBP-HA. NBP( $\left.2 \mathrm{mM}\right)$-HA and the indicated test substance or distilled water $(100 \mu \mathrm{L})$ were mixed by pipetting and the mixture left standing for $60 \mathrm{~min}$. Then, the mixture was centrifuged and the resultant supernatant was subjected to measurement of the NBP. Each value is the mean \pm S.D. from 4 tubes. $* p<0.05 v s$. distilled water group (data not shown).

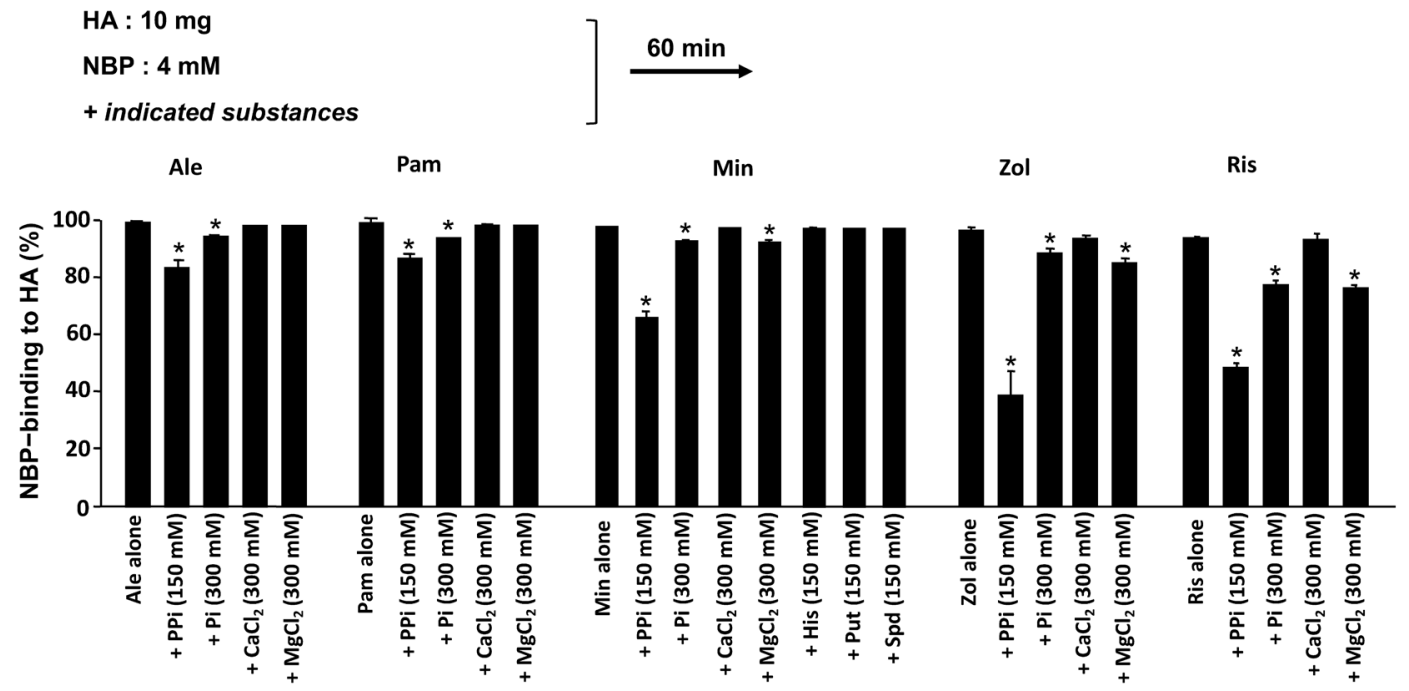

Fig. 7. Effects of PPi, $\mathrm{Pi}_{1} \mathrm{Ca}^{2+}, \mathrm{Mg}^{2+}$, and Amines on NBP-Binding to HA

HA $10 \mathrm{mg}$ and $100 \mu \mathrm{L}$ of the indicated test sample(s) were mixed by pipetting, and the mixture was left standing for $60 \mathrm{~min}$ before being centrifuged. Then, the NBP in the resultant supernatant was measured. Each value is the mean \pm S.D. from 4 tubes. $* p<0.05 v s$. NBP alone.

the entry of the released NBP into soft-tissue cells might be minor, if any. However, if all bones are saturated with an NBP, entry of the released NBP into soft-tissue cells and/or its excretion might occur to a significant extent. The ratio between these two events would differ depending on the degree of saturation with NBPs as well as on the doses of adminis- 


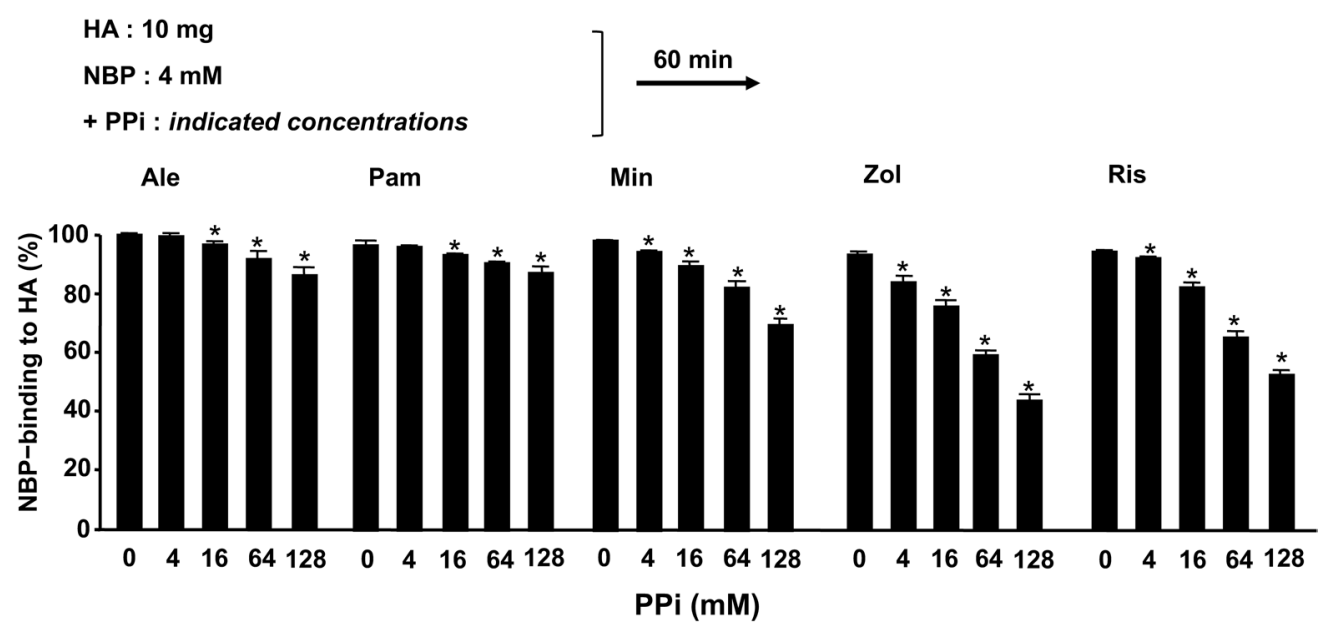

Fig. 8. Effects of PPi Concentration on NBP-Binding to HA

HA $10 \mathrm{mg}$ and $100 \mu \mathrm{L}$ of a solution containing $4 \mathrm{mM}$ of an NBP and the indicated concentration of PPi were mixed by pipetting, and the mixture was left standing for 60 min before being centrifuged. Then, the NBP in the resultant supernatant was measured. Each value is the mean \pm S.D. from 4 tubes. * $p<0.05$ vs. 0 (no PPi).

Table 1. Summary of the Findings in the Present Study

\begin{tabular}{llc}
\hline \hline \multirow{2}{*}{ Test substances } & \multicolumn{2}{c}{ Effects of test substances on } \\
\cline { 2 - 3 } Eti, Clo, PPi & Nnhibition & NBP-release from HA-bound NBPs \\
& Eti $>$ Clo (Fig. 2B) & Promotion \\
& & Eti $>>$ Clo (Fig. 3A) \\
& Eti $>$ Clo $>$ PPi for Ale and Pam (Figs. 4C, 6C) \\
Pi, PFA, PAA & Eti $\geq$ PPi $>$ Clo for Min, Zol, Ris (Figs. 4C, 6C) \\
& Inhibition & Promotion \\
$\mathrm{Ca}^{2+}, \mathrm{Mg}^{2+}$ & Very weak, if any (Fig. 7) & PPi $>$ PFA $>$ Pi $>$ PAA (Fig. 4C) \\
& Inhibition & Promotion \\
Amines* & Very weak, if any (Fig. 7) & Very weak, if any (Fig. 4C) \\
& No detectable effect (Fig. 7) & No detectable effects (Fig. 5B)
\end{tabular}

NBPs used in the present study were Ale, Pam, Min, Zol, and Ris. *Histamine, putrescine, and spermidine Note: 1. NBP-releasing effects and NBP-binding inhibitory effects of PPi are greater for Min, Zol, and Ris than for Ale and Pam (Figs. 6C, 8). 2. The effects of Pi, PFA, PAA, $\mathrm{Ca}^{2+}$, and $\mathrm{Mg}^{2+}$, and amines on NBP-binding to HA and NBP-release from NBP-bound HA are minimal, if any. 3. Under neutral conditions, NBPs bind to HA and the binding is saturable (1 mg HA is nearly saturated with 40 nmols of each NBP) (Figs. 1A, B). The velocities of both NBP-binding to HA and NBP-release from NBP-bound HA are very rapid at an unsaturated concentration of each NBP (Figs. 6A, B). 4. For complete binding to HA and for complete release from NBP-bound HA, Min and Zol require a somewhat longer standing time than Ale and Pam (Figs. 1B, 3C). 5. Although NBP-binding to HA was not modulated by pH under the conditions used (Fig. 2A), NBP-release from HA by Eti or PPi was modulated by pH (Figs. 4A, 5A). 6. The affinities for HA are NBPs (Ale, Pam, Min) $>>$ non-NBPs (Eti and Clo) (Figs. 3A, 4B).

tered non-NBPs or the amount of endogenous PPi present. It should be noted that bone scintigraphy using non-NBPs (the non-NBPs Med or Oxi) (see Supplementary Fig. 1) labeled with $99 \mathrm{mTc}$ is a useful method for detecting the sites in HA (i.e., in bones) to which $99 \mathrm{mTc}-\mathrm{BP}$ attaches, including when tumors, fractures, infection, and/or inflammation are present. Oral tissues are frequently exposed to bacteria, and bacteria are thought to trigger or promote BRONJ. ${ }^{22,23)}$ Notably, NBPs can be detected in the saliva of BRONJ patients, ${ }^{24)}$ indicating that jawbones are susceptible to the accumulation of BPs and may become saturated with a BP after its repeated administration. Therefore, the following scenarios need to be considered. (i) The NBPs released by PPi may enter soft-tissue cells, leading to BRONJ. (ii) The NBPs released by Eti and Clo may not enter soft-tissue cells because the co-presence of Eti and/or Clo inhibits SLC20 and/or SLC34. We discuss these ideas in the following paragraphs.

A reduction in alkaline phosphatase has been shown to result in an increase in PPi in the urine in both humans and mice. ${ }^{25,26)}$ Alkaline phosphatase is expressed on the cell mem- brane of osteoblasts, and NBPs are toxic to osteoblasts at $10^{-5}$ $M{ }^{27)}$ Thus, if NBPs reach $10^{-5} \mathrm{M}$ around jawbones, the number of osteoblasts might be reduced, resulting in an increase in PPi. It is also known that PPi is extracellularly produced by the hydrolysis of nucleotide triphosphates, including ATP, and ATP is released from nerve termini, immune cells, injured cells, and even from bacteria. ${ }^{28)}$ Interestingly, platelets store PPi in dense granules together with ATP. ${ }^{29)}$ A cell-wall component of Gram-negative bacteria, namely lipopolysaccharide (LPS), and the inflammatory cytokines interleukin (IL)-1 and tumor necrosis factor $\alpha$ (TNF- $\alpha$ ) are potent stimulators of platelets. ${ }^{30)}$ Thus, ATP and PPi may be increased at inflammatory, necrotic, and/or infected sites in the oral tissues of NBPtreated patients. Collectively, the above makes it seem likely that PPi-induced NBP-release occurs in NBP-accumulated jawbones, contributing to the development of BRONJ (Supplementary Fig. 4).

As shown in Supplementary Table 1, the non-NBPs Eti and Clo have a variety of properties in addition to their anti-boneresorptive effects. Taking these properties and the present 
findings into account, we now discuss the clinical applications of Eti and Clo.

(i) Eti as a Substitution Drug for NBPs to Treat and Prevent BRONJ: Once taken into cells, NBPs (dependent on their amounts) are cytotoxic for all cell types ${ }^{31)}$ because they inhibit the mevalonate pathway (common to all eukaryotic cells). ${ }^{32)}$ Here, we demonstrated that Eti releases NBPs from NBPbound HA. In addition, we previously demonstrated that NBPs enter cells via the phosphate transporters SLC20 and/or 34, and that Eti and Clo can inhibit this entry. ${ }^{15-17)}$ The anti-boneresorptive effect of Eti is far less powerful than those of NBPs (Supplementary Fig. 1). To compensate for this weak effect, Eti is used clinically at much larger doses (200-1000 mg) than NBPs (used at $1-50 \mathrm{mg}$ ). Thus, such a large dose of Eti would expel bone-bound NBPs from the bone and inhibit the entry of the released NBPs into soft-tissue cells around the jawbones. Consequently, Eti would be expected to be effective as a substitution drug for an NBP in patients with BRONJ or at risk of BRONJ. Indeed, our clinical attempts support this idea. ${ }^{18,19)}$ Eti might also be effective for preventing BRONJ if it is given orally or intravenously just prior to invasive dental treatments.

(ii) Eti as an Irrigating Agent during Invasive Dental Treatments in NBP-Treated Patients: Invasive dental treatments (e.g., tooth extraction, dental implants, apical/periodontal surgery) are thought to be risk or causal factors for BRONJ. ${ }^{8)}$ Interestingly, Eti has appeared recently on the market as a root canal-irrigating agent (brand name "Dual Rinse ${ }^{\circledR}$ HEDP"), ${ }^{33,34)}$ with the Eti being used at a very high concentration $[0.9 \mathrm{~g} / 10 \mathrm{~mL}(360 \mathrm{mM})]$. When injected into mouse earpinnas $(20 \mu \mathrm{L} / \mathrm{ear})$, Eti does not exhibit inflammatory/necrotic effects even at $100 \mathrm{mM} .{ }^{35)}$ On the contrary, Eti, when injected together with an NBP, inhibits the NBP-induced inflammation by inhibiting its entry into cells. For example, $16-50 \mathrm{mM}$ Eti completely prevents the inflammatory/necrotic effects of 2-4 mM Zol. ${ }^{13,17)}$ Thus, irrigation with a solution including a high concentration of Eti might be a safe and effective method for reducing jawbone-accumulated NBPs. As shown in Figs. $4 \mathrm{~A}$ and $5 \mathrm{~A}$, release of an NBP (Ale, Pam, or Zol, but not Min) from NBP-HA is greater at higher $\mathrm{pH}$. Thus, an Eti solution with a higher $\mathrm{pH}$ (possibly around $\mathrm{pH}$ 9) may be very suitable as an irrigating solution for removing jawbone-bound NBPs (Ale, Pam, or Zol). Interestingly, Hokugo et al. recently reported that in Zol-treated mice, injections of Eti around a tooth one day before its extraction reduced the development of jawbone necrosis. ${ }^{36)}$ The same authors previously (2013) showed by in vitro experiments using fluorophore-conjugated NBPs that a BP and HA would establish an equilibrium, and thus an additional application of a BP may partially replace the BP while maintaining the equilibrium. ${ }^{37)}$

(iii) Clo as a Preventive Drug against BRONJ: The affinity of Clo for HA is the lowest among BPs and lower than that of PPi (Supplementary Table 2), and its ability to release NBPs from HA is much weaker than that of Eti. In our in vivo studies in mice, although Eti reduces the anti-bone-resorptive activities of $\mathrm{NBPs},{ }^{12,35)}$ Clo does not reduce them. ${ }^{11,13)} \mathrm{Clo}$ does, however, prevent or reduce the inflammatory/necrotic effects of NBPs by inhibiting NBPs' entry into cells via the phosphate transporters SLC20 and/or SLC34, and this effect is stronger than that of Eti. ${ }^{14,15,38,39)}$ Thus, a combination of Clo and an NBP might be effective for preventing BRONJ while preserving the powerful anti-bone-resorptive effect of the NBP. Moreover, Clo and Eti have analgesic effects that are independent of their anti-bone-resorptive effects and are derived from inhibition of the phosphate transporter SLC17..$^{15,40-45)}$ The analgesic effect of Clo is also greater than that of Eti. ${ }^{40,43)}$

The affinities for HA are NBPs (Ale, Pam, Min) $>>$ nonNBPs (Eti and Clo) (Figs. 3A, 4B). So, the results shown in Fig. 4B suggest that if these NBPs were given to patients who had previously been treated with non-NBPs for the removal of NBPs (to prevent or treat BRONJ), the non-NBPs may then be replaced with NBPs, i.e., restoring the potent anti-boneresorptive effects of NBPs.

Eti and Clo were the first BPs reported as possible drugs following collaborations between Fleisch and Francis. ${ }^{46)}$ Eti (synthesized as early as 1897) has recently undergone reappraisal because it has various properties that appear unique vs. NBPs and it has a host of "off-label" uses. ${ }^{47)}$ Clo has also been reappraised because of its variety of effects (including its analgesic effect) and because of the availability of various administration routes (including intramuscular injection) and its tolerability or safety. ${ }^{10,48,49)}$

Within the last few years, NBPs have been studied as drugs for preventing the non-gravity-induced osteoporosis that occurs during a prolonged stay in space, supporting NBPs being very important drugs available for preventing osteoporosis. Therefore, establishing methods for their safe use is critical. In conclusion, our findings may contribute to this. Although NBPs have been thought to undergo stable binding to bone, and thus to have a long half-life in bone, the present results suggest that NBPs might be released from NBP-accumulated jawbones by PPi produced in the environment of the jawbones, leading to the development of BRONJ.

Acknowledgments Research funding provided by Japan Society for Promotion of Science (18K17240 and 21K10157 to KB). The authors are grateful to Dr. Robert Timms, a former language-editor of J. Physiol. (Lond.), who edited our manuscripts throughout our studies and provided many instructive suggestions. We also thank the Biomedical Research Core of Tohoku University Graduate School of Medicine for the use of its equipment.

Conflict of Interest The authors declare no conflict of interest.

Supplementary Materials The online version of this article contains supplementary materials.

\section{REFERENCES}

1) Fleisch H. Bisphosphonates: preclinical aspects and use in osteoporosis. Ann. Med., 29, 55-62 (1997).

2) Fleisch H. Bisphosphonates: mechanisms of action. Endocr. Rev. 19, 80-100 (1998).

3) Russell RGG, Xia Z, Dunford JE, Oppermann U, Kwaasi A, Hulley PA, Kavanagh KL, Triffitt JT, Lundy MW, Phipps RJ, Barnett BL, Coxon FP, Rogers MJ, Watts NB, Ebetino FH. Bisphosphonates: an update on mechanisms of action and how these relate to clinical efficacy. Ann. N. Y. Acad. Sci., 1117, 209-257 (2007).

4) Geddes AD, D'Souza SM, Ebetino FH, Kenneth JI. Bisphosphonates: structure-activity relationships and therapeutic implications. Bone and Mineral Research. (Heershe NM, Kanis JK ed). Vol. 8, 
Elsevier Science BV, Amsterdam, Holland, pp. 265-306 (1994).

5) Marx RE. Pamidronate (Aredia) and zoledronate (Zometa) induced avascular necrosis of the jaws: a growing epidemic. J. Oral Maxillofac. Surg., 61, 1115-1117 (2003).

6) Migliorati CA. Bisphosphonates and oral cavity avascular bone necrosis. J. Clin. Oncol., 21, 4253-4254 (2003).

7) Fliefel R, Tröltzsch M, Kühnisch J, Ehrenfeld M, Otto S. Treatment strategies and outcomes of bisphosphonate-related osteonecrosis of the jaw (BRONJ) with characterization of patients: a systematic review. Int. J. Oral Maxillofac. Surg., 44, 568-585 (2015).

8) Yoneda $\mathrm{T}$, Hagino $\mathrm{H}$, Sugimoto $\mathrm{T}$, Ohta $\mathrm{H}$, Takahashi $\mathrm{S}$, Soen $\mathrm{S}$, Taguchi A, Nagata T, Urade M, Shibahara T, Toyosawa S. Antiresorptive agent-related osteonecrosis of the jaw: Position Paper 2017 of the Japanese Allied Committee on Osteonecrosis of the Jaw. $J$. Bone Miner. Metab., 35, 6-19 (2017).

9) Endo Y, Kumamoto H, Nakamura M, Sugawara S, Takano-Yamamoto T, Sasaki K, Takahashi T. Underlying mechanisms and therapeutic strategies for bisphosphonate-related osteonecrosis of the jaw (BRONJ). Biol. Pharm. Bull., 40, 739-750 (2017).

10) Nardi A, Ventura L, Cozzi L, Tonini G. Clodronate news of efficacy in osteoporosis. Clin. Cases Miner. Bone Metab., 13, 33-35 (2016).

11) Funayama H, Ohsako M, Monma $Y$, Mayanagi H, Sugawara S, Endo Y. Inhibition of inflammatory and bone-resorption-inhibitory effects of alendronate by etidronate. Calcif. Tissue Int., 76, 448-457 (2005).

12) Monma Y, Funayama H, Mayanagi H, Endo Y. Effects of weekly administrations of alendronate + clodronate on young mouse tibia: localized action at the proximal growth plate. Calcif. Tissue Int., $\mathbf{7 4}$, 115-121 (2004)

13) Oizumi $T$, Funayama $H$, Yamaguchi $Y$, Yokoyama M, Takahashi $\mathrm{H}$, Yamamoto M, Kuroishi T, Kumamoto H, Sasaki K, Kawamura $\mathrm{K}$, Sugawara S, Endo Y. Inhibition of necrotic actions of nitrogencontaining bisphosphonates (NBPs) and their elimination from bone by etidronate (a Non-NBP): a proposal for possible utilization of etidronate as a substitution drug for NBPs. J. Oral Maxillofac. Surg., 68, 1043-1054 (2010).

14) Endo Y, Shibazaki M, Yamaguchi K, Nakamura M, Kosugi H. Inhibition of inflammatory actions of aminobisphosphonates by dichloromethylene bisphosphonate, a non-aminobisphosphonate. $\mathrm{Br} . J$. Pharmacol., 126, 903-910 (1999).

15) Okada S, Kiyama T, Sato E, Tanaka Y, Oizumi T, Kuroishi T, Takahashi T, Sasaki K, Sugawara S, Endo Y. Inhibition of phosphate transporters ameliorate the inflammatory and necrotic side effects of the nitrogen-containing bisphosphonate zoledronate in mice. Tohoku J. Exp. Med., 231, 145-158 (2013).

16) Kiyama T, Tsuchiya M, Okada S, Oizumi T, Yamaguchi K, Sasaki $\mathrm{K}$, Sugawara S, Endo Y. Phosphonocarboxylates can protect mice against the inflammatory and necrotic side effects of nitrogencontaining bisphosphonates by inhibiting their entry into cells via phosphate transporters. Biol. Pharm. Bull., 39, 712-720 (2016).

17) Shima K, Tsuchiya M, Oizumi T, Takano-Yamamoto T, Sugawara $\mathrm{S}$, Endo Y. Inflammatory effects of nitrogen-containing bisphosphonates (N-BPs): modulation by non-N-BPs. Biol. Pharm. Bull., 40, 25-33 (2017).

18) Yamaguchi K, Oizumi T, Funayama H, Kawamura H, Sugawara $S$, Endo Y. Osteonecrosis of the jawbones in 2 osteoporosis patients treated with a nitrogen-containing bisphosphonate: osteonecrosis reduction replacing NBP with non-NBP (etidronate) and rationale. $J$. Oral Maxillofac. Surg., 68, 889-897 (2010).

19) Oizumi T, Yamaguchi K, Sato K, Takahashi M, Yoshimura G, Otsuru H, Tsuchiya M, Hagiwara Y, Itoi E, Sugawara S, Takahashi T, Endo Y. A strategy against the osteonecrosis of the jaw associated with nitrogen-containing bisphosphonates (N-BPs): attempts to replace N-BPs with the non-N-BP etidronate. Biol. Pharm. Bull., 39, 1549-1554 (2016).

20) Endo Y. Simple method for the simultaneous determination of his- tamine, polyamines and histone H1. J. Chromatogr., 205, 155-164 (1981).

21) Mönkkönen J, Koponen H-M, Ylitalo P. Comparison of the distribution of three bisphosphonates in mice. Pharmacol. Toxicol., 66, 294-298 (1990)

22) Hellstein JW, Marek CL. Bisphosphonate osteochemonecrosis (bisphossy jaw): is this phossy jaw of the 21st century? J. Oral Maxillofac. Surg., 63, 682-689 (2005).

23) Migliorati CA, Siegel MA, Elting LS. Bisphosphonate-associated osteonecrosis: a long-term complication of bisphosphonate treatment. Lancet Oncol., 7, 508-514 (2006).

24) Scheper MA, Badros A, Salama AR, Warburton G, Cullen KJ, Weikel DS, Meiller TF. A novel bioassay model to determine clinically significant bisphosphonate levels. Support. Care Cancer, 17, 1553-1557 (2009).

25) Whyte MP, Landt M, Ryan LM, Mulivor RA, Henthorn PS, Fedde KN, Mahuren JD, Coburn SP. Alkaline phosphatase: placental and tissue-nonspecific isoenzymes hydrolyze phosphoethanolamine, inorganic pyrophosphate, and pyridoxal 5'-phosphate. Substrate accumulation in carriers of hypophosphatasia corrects during pregnancy. J. Clin. Invest., 95, 1440-1445 (1995).

26) Fedde KN, Blair L, Silverstein J, Coburn SP, Ryan LM, Weinstein RS, Waymire K, Narisawa S, Millán JL, MacGregor GR, Whyte MP. Alkaline phosphatase knock-out mice recapitulate the metabolic and skeletal defects of infantile hypophosphatasia. J. Bone Miner. Res., 14, 2015-2026 (1999).

27) Bellido T, Plotkin LI. Novel actions of bisphosphonates in bone: preservation of osteoblast and osteocyte viability. Bone, 49, 50-55 (2011).

28) Inami A, Kiyono H, Kurashima Y. ATP as a pathophysiologic mediator of bacteria-host crosstalk in the gastrointestinal tract. Int. J. Mol. Sci., 19, 2371 (2018).

29) Silcox DC, Jacobelli S, Mccarty DJ. Identification of inorganic pyrophosphate in human platelets and its release on stimulation with thrombin. J. Clin. Invest., 52, 1595-1600 (1973).

30) Yu Z, Shibazaki M, Otsuka H, Takada H, Nakamura M, Endo Y. Dynamics of platelet behaviors as defenders and guardians: accumulations in liver, lung, and spleen in mice. Biol. Pharm. Bull., 42, 1253-1267 (2019).

31) Tanaka Y, Nagai Y, Dohdoh M, Oizumi T, Ohki A, Kuroishi T, Sugawara S, Endo Y. In vitro cytotoxicity of zoledronate (nitrogencontaining bisphosphonate: NBP) and/or etidronate (non-NBP) in tumor cells and periodontal cells. Arch. Oral Biol., 58, 628-637 (2013).

32) Rogers MJ, Crockett JC, Coxon FP, Mönkkönen J. Biochemical and molecular mechanisms of action of bisphosphonates. Bone, 49 34-41 (2011).

33) Ballal NV, Das S, Rao BSS, Zehnder M, Mohn D. Chemical, cytotoxic and genotoxic analysis of etidronate in sodium hypochlorite solution. Int. Endod. J., 52, 1228-1234 (2019).

34) Giardino L, Del Fabbro M, Morra M, Pereira T, Bombarda de Andrade F, Savadori P, Generali L. Dual Rinse HEDP increases the surface tension of $\mathrm{NaOCl}$ but may increase its dentin disinfection efficacy. Odontology, 107, 521-529 (2019).

35) Oizumi T, Yamaguchi K, Funayama H, Kuroishi T, Kawamura $\mathrm{H}$, Sugawara S, Endo Y. Necrotic actions of nitrogen-containing bisphosphonates and their inhibition by clodronate, a non-nitrogencontaining bisphosphonate in mice: potential for utilization of clodronate as a combination drug with an NBP. Basic Clin. Pharmacol. Toxicol., 104, 384-392 (2009).

36) Hokugo A, Kanayama K, Sun S, Morinaga K, Sun Y, Wu Q, Sasaki H, Okawa H, Evans C, Ebetino FH, Lundy MW, Sadrerafi K, McKenna CE, Nishimura I. Rescue bisphosphonate treatment of alveolar bone improves extraction socket healing and reduces osteonecrosis in zoledronate-treated mice. Bone, 123, 115-128 (2019). 37) Hokugo A, Sun S, Park S, McKenna C-E, Nishimura I. Equilib- 
rium-dependent bisphosphonate interaction with crystalline bone mineral explains anti-resorptive pharmacokinetics and prevalence of osteonecrosis of the jaw in rats. Bone, 53, 59-68 (2013).

38) Yu Z, Funayama H, Deng X, Kuroishi T, Sasano T, Sugawara S, Endo Y. Comparative appraisal of clodronate, aspirin and dexamethasone as agents reducing alendronate-induced inflammation in a murine model. Basic Clin. Pharmacol. Toxicol., 97, 222-229 (2005).

39) Shikama Y, Nagai Y, Okada S, Oizumi T, Shimauchi H, Sugawara $\mathrm{S}$, Endo Y. Pro-IL-1 $\beta$ accumulation in macrophages by alendronate and its prevention by clodronate. Toxicol. Lett., 199, 123-128 (2010).

40) Kim S, Seiryu M, Okada S, Kuroishi T, Takano-Yamamoto T, Sugawara S, Endo Y. Analgesic effects of the non-nitrogen-containing bisphosphonates etidronate and clodronate, independent of antiresorptive effects on bone. Eur. J. Pharmacol., 699, 14-22 (2013).

41) Bonabello A, Galmozzi MR, Bruzzese T, Zara GP. Analgesic effect of bisphosphonates in mice. Pain, 91, 269-275 (2001).

42) Fujita T, Ohue M, Fujii Y, Miyauchi A, Takagi Y. Comparison of the analgesic effects of bisphosphonates: etidronate, alendronate and risedronate by electroalgometry utilizing the fall of skin impedance. J. Bone Miner. Metab., 27, 234-239 (2009).

43) Shima K, Nemoto W, Tsuchiya M, Tan-No K, Takano-Yamamoto T, Sugawara S, Endo Y. The bisphosphonates clodronate and etidronate exert analgesic effects by acting on glutamate- and/or ATP- related pain transmission pathways. Biol. Pharm. Bull., 39, 770-777 (2016).

44) Kato Y, Hiasa M, Ichikawa R, Hasuzawa N, Kadowaki A, Iwatsuki K, Shima K, Endo Y, Kitahara Y, Inoue T, Nomura M, Omote $\mathrm{H}$, Moriyama Y, Miyaji T. Identification of a vesicular ATP release inhibitor for the treatment of neuropathic and inflammatory pain. Proc. Natl. Acad. Sci. U.S.A., 114, E6297-E6305 (2017).

45) Yamagata R, Nemoto W, Nakagawasai O, Hung W-Y, Shima K, Endo Y, Tan-No K. Etidronate attenuates tactile allodynia by spinal ATP release inhibition in mice with partial sciatic nerve ligation. Naunyn Schmiedebergs Arch. Pharmacol., 392, 349-357 (2019).

46) Francis MD, Graham R, Russell G, Fleisch H. Diphosphonates inhibit formation of calcium phosphate crystals in vitro and pathological calcification in vivo. Science, 165, 1264-1266 (1969).

47) Watts NB, Chesnut CH III, Genant HK, Harris ST, Jackson RD, Licata AA, Miller PD, Mysiw WJ, Richmond B, Valent D. History of etidronate. Bone, 134, 115222 (2020).

48) Frediani B, Bertoldi I. Clodronate: new directions of use. Clin. Cases Miner. Bone Metab., 12, 97-108 (2015).

49) Saviola G, Abdi-Ali L, Povino MR, Campostrini L, Sacco S, Carbonare LD. Intramuscular clodronate in erosive osteoarthritis of the hand is effective on pain and reduces serum COMP: a randomized pilot trial: the ER.O.D.E. study (Erosive Osteoarthritis and Disodium-clodronate Evaluation). Clin. Rheumatol., 36, 2343-2350 (2017). 